\title{
INFLUENCE OF COAXIAL SWIRLING LIQUID FLOW ON INTERNAL MIXING AIR-ASSISTED ATOMIZER
}

\author{
M. A. O. Shehata, A. Abd Elmotalip \\ Mechanical Power Engineering Department, Faculty of Engineering, \\ Port Said University, Egypt
}

\begin{abstract}
The present work is devoted experimentally to determine the behavior of the flow of both air and water in an internal mixing air-assisted atomizer with swirling coaxial liquid, pointing the attention on the optimization of some geometrical parameters. Some experiments have been performed for air central channel diameter and coaxial liquid port, as well as for several experimental conditions (air and water pressures), this is an important result that will help in the optimum design of this type of atomizer.

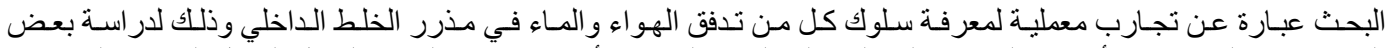

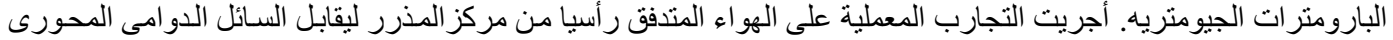

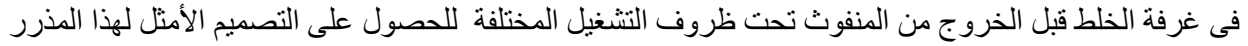

\section{INTRODUCTION}

The atomizer is a key of the liquid fuel combustion system. In many industrial applications such as spray-drying, exhaust cleaning and combustion, well defined spray characteristics and a wide flow rate operation range are required. In most cases airassisted atomizers are able to fulfill these requirements and are used, therefore, despite their additional energy consumption. As a group, air assisted atomizers can be divided into internal and external mixing types, depending on where the first contact between the liquid and gas phase takes place. From this category, the Y-Jet atomizer, the mixing chamber atomizer, the effervescent atomizer and the internal-mixing atomizer with coaxial liquid feed are the most common ones in chemical engineering and combustion applications. The last of these will be the subject of this paper. A method of twin-fluid atomization employing internal mixing has been used by some workers [1-3]. In this type, gas and liquid are mixed in a mixing chamber before being discharged through an exit port where the final atomization takes place. These atomizers have advantages over pressure swirl ones, especially in combustion system applications, which operate at high pressures [3]. As it is noted by Lefebvre [1] the principle of the air-blast atomizer operation is exactly the same as the air-assist atomizer. The wide range of the swirl and air-assist atomizers applications motivated extensive studies for their design. Relationships between discharge coefficient, film thickness, flow number and atomizer dimensions were investigated by Carlislee [4], Dombrowski and Hassan [5], Rizk and Lefebvre [6], Jones [7], Sunharan et al. [8], Havkin [9], Simmons and Harding [10] and others. Many researchers investigated the effect of liquid and gas properties and the physical and geometric parameters of the airblast atomizers on droplet size. Lefebvre [3] has shown that varying the air to liquid ratio (ALR) over a range from 3 to 9 had little effect on atomization quality. Levy et al. [11] observed only little effect whenever the ALR was more than 1. Similar results were obtained by Fraser et al [12], but the lower value was about 1.5. Effect of swirler parameters on air flow at the nearby region of the air exit was studied by Beer and Chieger [13], Mathur and Maccalum [14], Klik [15] and Ferreira et al. [16]. It was shown that there is a recirculation region with an associated pressure zone. The atomization system consider in the present work is based on the design of air-assist atomizer. In this paper the study of the behavior of the flow of both air and water in twinfluid nozzle with an internal mixing chamber, pointing the attention on the optimization of some geometrical parameters that have a considerable influence on its correct performance. Experiments have been performed for air central channel diameter and liquid ports geometries, as well as for various air and liquid pressures.

Results obtained will help in the optimal design of this kind of nozzles. 


\section{EXPERIMENTAL TEST-RIG}

The experimental arrangement is shown in Fig.(1). The rig was designed to study the influence of various parameters on the performance such as, air pressure, water pressure, swirl angle and mixing chamber length (L).

In order to carry out a complete analysis of the two fluid flows inside the nozzle, experiments of some specific parameters are needed. For this reason, several devices and techniques have been used in this research. Two different pieces, an inner and an outer part, which form an internal mixing chamber when are assembled. The outer part is a conical hollow piece with one exit hole with a diameter of $1 \mathrm{~mm}$. The inner face of this piece, which forms the base of the mixing chamber, has a conical shape with different swirl angle. For all the experiments the same external piece has been used.

On the other hand, the inner part has a truncatedcone shape with 6 swirl slots of rectangular cross section. In order to study the influence of the liquid ports on the behavior of the spray, their slant angle with respect to main axis have been changed from 0 , 15,30 and 45 degree (axial aligned), shown in photo (1).

The width-to-height ratio $(\mathrm{b} / \mathrm{h})$ of swirl slots of rectangular cross section has been tested namely (5.3 33$) \mathrm{mm}$ keeping constant the cross sectional of the slot (15.9) $\mathrm{mm}^{2}$. On the other hand, the influence of the air flow has also been the air central discharge diameter at $2 \mathrm{~mm}$. All the experiments have been performed using water and air as atomized and atomizing fluids, respectively, the parts and assembly of atomizer are shown in photos (2) and (3).

The nozzle has been assembled in the test-rig as shown in Fig.(2), and the spray pattern is shown in photo (4). Air is supplied with a compressor that provides a maximum flow rate at $10 \mathrm{bar}$, and a gear pump is used to supply the water. In the experiments, for a constant water pressure, different air pressures have been established. The aim of this work is to establish a direct comparison for the different slot angles of inner part.

The results obtained should be valid, having in mind that all the configuration are tested under the same conditions.

Water is discharged from a gear pump through a filter and controlled by using a by-pass valve. The air is discharged through a compressor passed through a control valve and a Bourdon gauge. Both water and air are mixed and collected in a cone chamber, Fig.(2).

\section{RESULTS AND DISCUSSIONS}

The influence of the swirl angle of the liquid ports on the spray cone angle and spray distribution is plotted in Fig.(3) to Fig. (6), which the air central channel diameter is the same in all cases. The influence of the produce swirl motion in the internal mixing chamber due to the slant angle of the liquid ports, is shown in Fig.(3). In this case contrary to what could have been expected, the slant angles of the liquid ports have a small improve in the behavior of the nozzle. The most likely reason for this effect is that the main process determining the atomization is the strong interaction and mixing of the two fluids at the internal mixing chamber. Even if the liquid is rotating inside the chamber, the path followed before entering the exit hole must be too small for the swirl to affect the nozzle performance. It could be expected that a torrid structure that rotates around the main axis of the nozzle is formed into the mixing chamber due to interaction of the water and air flows.

The cone shape spray is one of the studied characteristic and used to determine the efficient atomization or combustion of fuel.

The spray was illuminated evenly from both sides and a video camera was used to capture spray images. The edges of the spry were visually determined from the spray images played back on a TV monitor and the width of the spray cone angle was measured at $\mathrm{H}=40 \mathrm{~mm}$ downstream of the injection exit orifice.

Spray cone angles were calculated from this width using simple trigonometry, $\Theta=2 \tan ^{-1}(\mathrm{~W} / 2 \mathrm{H})$, where $\mathrm{W}$ is the spray width in millimeters. The spray cone angle is plotted versus swirl angle at a fixed water pressure 4 bar, in Figs.(3) and (4). Each plot has five series of points corresponding to five different air pressures and length of mixing chamber from 3 to 7 $\mathrm{mm}$, reported as mean values plus or minus of the maximum deviation.

The effect of injection air pressure on cone angle is also evident from Fig.(3). At the lowest air pressure tested 4 bar, the spray cone angle lies between 9 and $16^{0}$ for the entire range of swirl angles and air pressures. At a greater air pressure, $5 \mathrm{bar}$, the range is 23 and $27^{\circ}$. Figs.(3) and (4) show that the cone angle increases fairly with swirl angle, mixing chamber length, and air pressure increasing except at air pressure equal 4 bar, see Fig.(4).

The spatial distribution of spray produced was measured experimentally with a patternator, a device consisting of a set of test tubes uniformly distributed at a certain vertical distance $(30 \mathrm{~cm})$ from the nozzle tip. To obtain the desired data from the simulations, the front outlet boundary of the considered domain was divided into region`s with surface equivalent to a patternation test tube. The mass flow rate passing through each region was measured and related to the global mass flow rate providing values easily comparable with experimental results. Figures (5) and (6) present the effect of air pressure to water pressure ratio and swirl angle on the radial distribution of the liquid mass concentration with 
mixing chamber equal $3 \mathrm{~mm}$ and $30 \mathrm{~cm}$ as the height from the nozzle tip to measure level. The figures show that, the increasing of $\left(\frac{P a}{P_{w}}\right)$ ratio and swirl angle decreases the peak value of mass concentration percentage and shifts its radial location outwards, and increases the spray diameter.

The formula of the spray angle $(\theta)$ for the given geometries is given by:

$$
\theta=3.0 \ln (\mathrm{S} . \mathrm{L})\left(\frac{P a}{P w}\right)^{2.5} \text { for } \mathrm{S}>0
$$

where, S, L, $\mathrm{p}_{\mathrm{a}}$ and $\mathrm{p}_{\mathrm{w}}$ are swirl angle (degrees), mixed chamber length $(\mathrm{mm})$, air pressure and water pressure respectively. The comparison of the spray angle between the experimental data and calculated results from the formula was shown in Fig.(7). In most cases the correlation is seen to predict spray angle fairly accurately.

\section{CONCLUSIONS}

This experimental research has been devoted to the different air pressures, swirl angles and mixing chamber length.

-As the swirl angles, air pressures and mixing chamber length increased, spray cone angle increases.

This study contributes to the spray patternation understanding by presenting a very simple justifiable, method capable of determine the spray pattern in an accurate and economic way.

-Increasing the spray cone angle shifts the radial position of the peak value of the water concentration outward. The peak value of liquid concentration is increased by decreasing the $\left(\frac{P a}{P w}\right)$ ratio, as well as, the swirl angle.

- An empirical formula was obtained including swirl angle, mixing chamber length, air pressure and water pressure.

$$
\theta=3.0 \ln (\mathrm{S} . \mathrm{L})\left(\frac{P a}{P_{w}}\right)^{2.5} \text { for } \mathrm{S}>0
$$

\section{REFERENCES}

[1] Lefebvre, A.H., 1999, Gas turbine combustion, Tailer\&Fransis PA,USA.

[2] Lefebvre, A., H., 2000, " Fifty years of gas turbine fuel injection", Atomization and Spray.,10,pp. 251-276.

[3] Lefebvre, A., H., Atomization and sprays, Hemisphere, publishing Co., 1989.

[4] Carlislee, D.,R., 1955, "Communication on the performance of a type of swirl atomization", Proceeding institute of mechanical engineering, 169, pp. 101.
[5] Dombrowski, N. and Hassan, D., 1969, " The flow characteristics of swirl centrifugal spray pressure nozzle with low viscosity liquids", AIChE Journal, 15, p.604.

[6] Rizk, N.K., Lefebvre,A.H., 1985, "Internal flow characteristics of simplex swirl atomizers", AIAA Journal propulsion and power, 1, No.3, pp. 193-199.

[7] Jones, A.R., 1982, " Design optimization of a large pressure-Jet atomizer for power plant" , proceeding of the international conference on liquid atomization and spray systems, Madison, pp.181-185.

[8] Sunharan Kutty, P.,Narasimhan, M.V., and Narayanaswany, K., 1978 , "Design and production of discharge rate cone angle and air cone diameter of swirl chamber atomizer", Proceeding of the $1^{\text {st }}$ international conference on liquid atomization and spray systems, Tokyo, pp.93-100.

[9] Havkin, Y. I., 1978, Ztentrobezhnie Fosunki (swirl Atomizers), Moscow.

[10] Simmons, H. C., Harding, C. F., 1980, "Some effects on using water as a test fluid in fuel spray Nozzles Analysis", ASME Paper, 80-GT-90.

[11] Levy, Y., Sherbaum V., Levin D., and Ovcharenko V., 2005, "Airblast swirl atomizer for small jet engine" ASME Turbo Expo 2005, GT 2005-68314.

[12] Fraser, R. P., Dombrowski, N., Routley, J. H., 1963, "The Atomization of a liquid film by an impinging air stream", Chemical Engineering Sciences", pp. $339-353$.

[13] Beer, J. M., and Chieger, N. A., 1972, Combustion aerodynamics, Applied Science, London.

[14] Mathur, M. L., and Maccallum, N. R. L.,1967, “ Swirling air jets issuing from air swirlers", part 1, Free Jets, " Journal of Institute of Fuel, Vol. 40, pp. 214-225.

[15] Kilik, E., 1976, "The Influence of swirl design parameters on the aerodynamics of the downstream recirculation region", $\mathrm{PhD}$ thesis, School of Mechanical Engineering, Cranfield Institute of Technology, England.

[16] Ferreira, G., Garcia, J.A., Berreras, F., Lozano, A. and Lincheta, E., "Design optimization of twin- fluid atomizers with an internal mixing chamber for heavy fuel oils". Fuel Proceeding Technology 90 (2009), pp.270-278. 
M. A. O. Shehat and A. Abd Elmotalip, "Influence of Coaxial Swirling Liquid Flow on Internal Mixing ..."

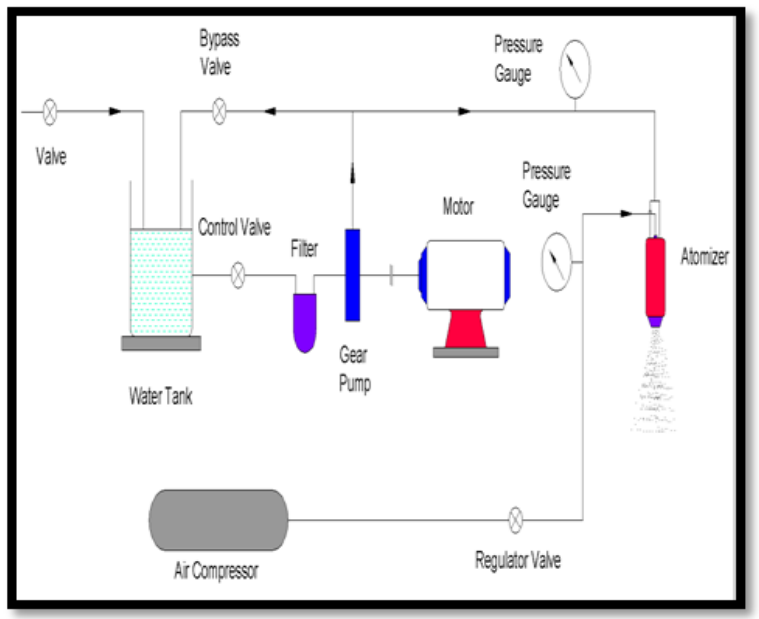

Fig. 1 Schematic of Test-rig

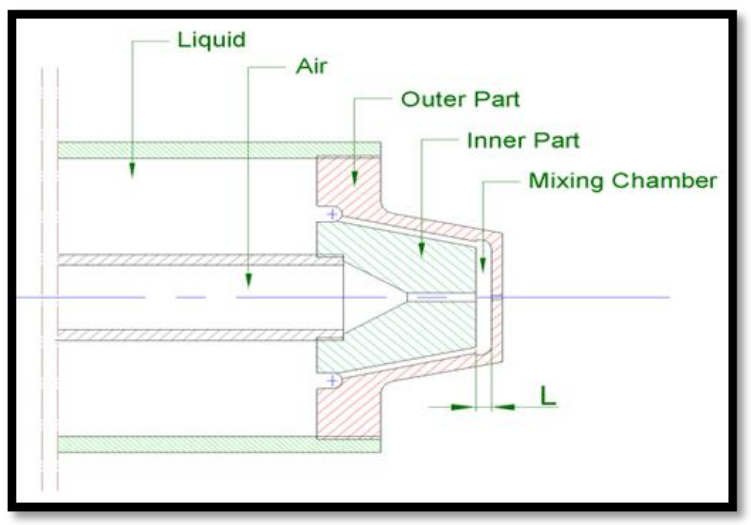

Fig. 2 Sketch of the nozzle

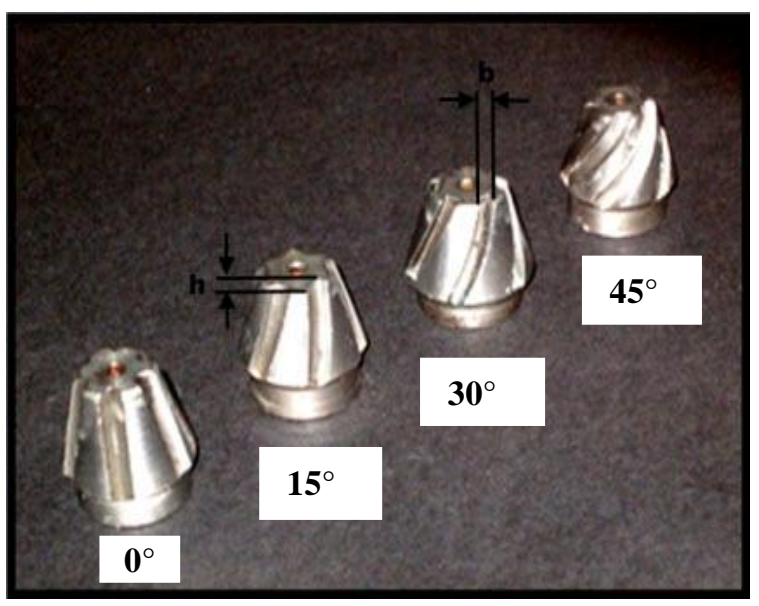

Photo (1) Different swirl angles

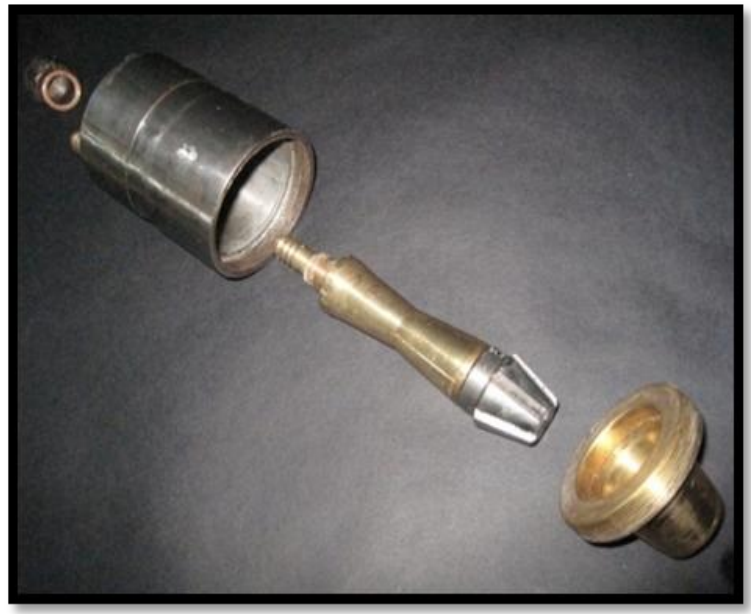

Photo (2) Atomizer parts

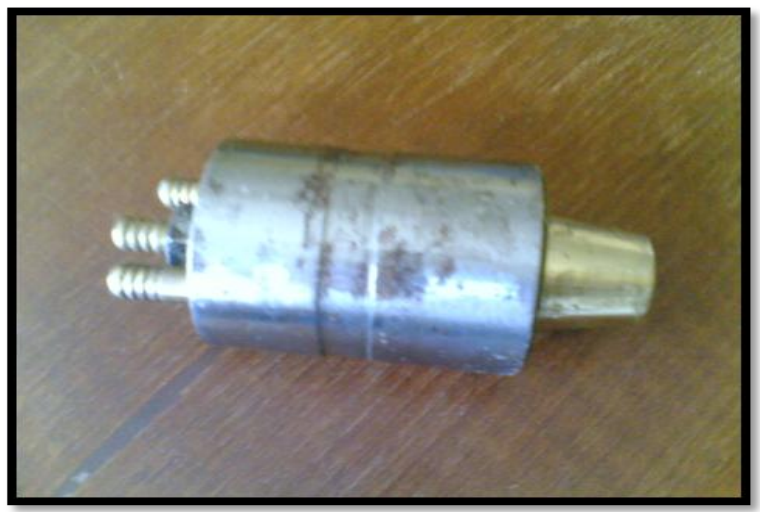

Photo (3) Atomizer assembly

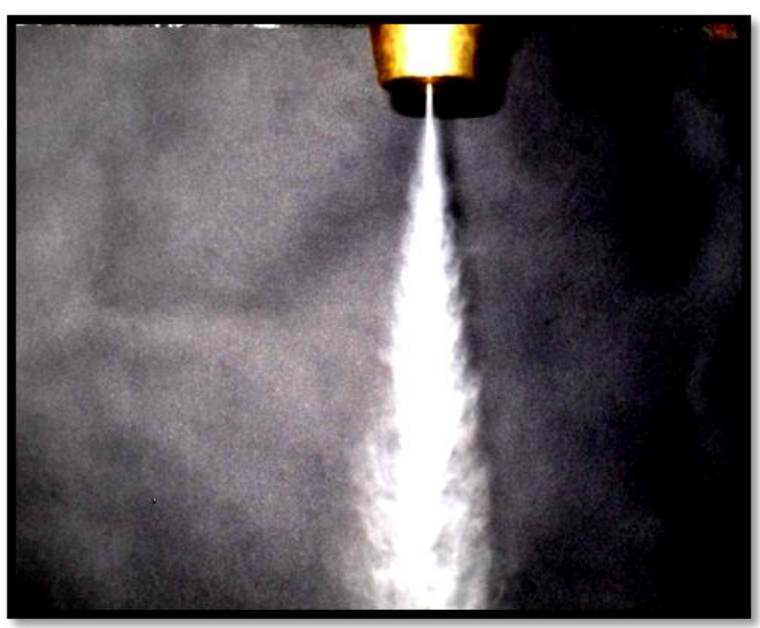

Photo (4) Spray pattern 


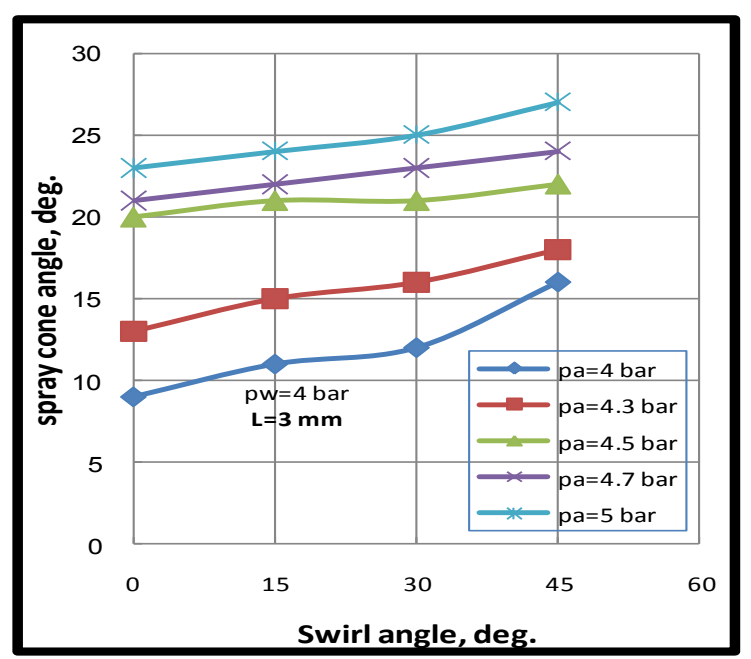

Fig. 3 Effect of swirl angle on the spray cone angle

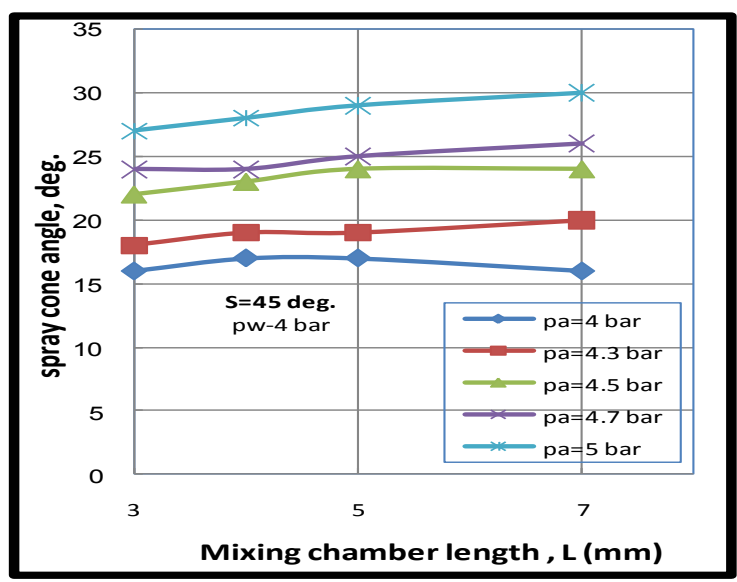

Fig. 4 Effect of mixing chamber length on the spray cone angle

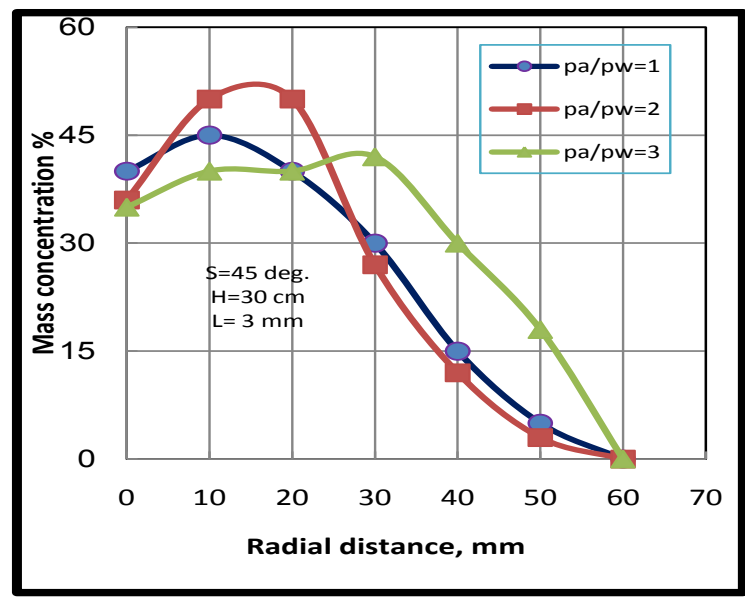

Fig. 5 Effect of pressure ratio on the mass concentration

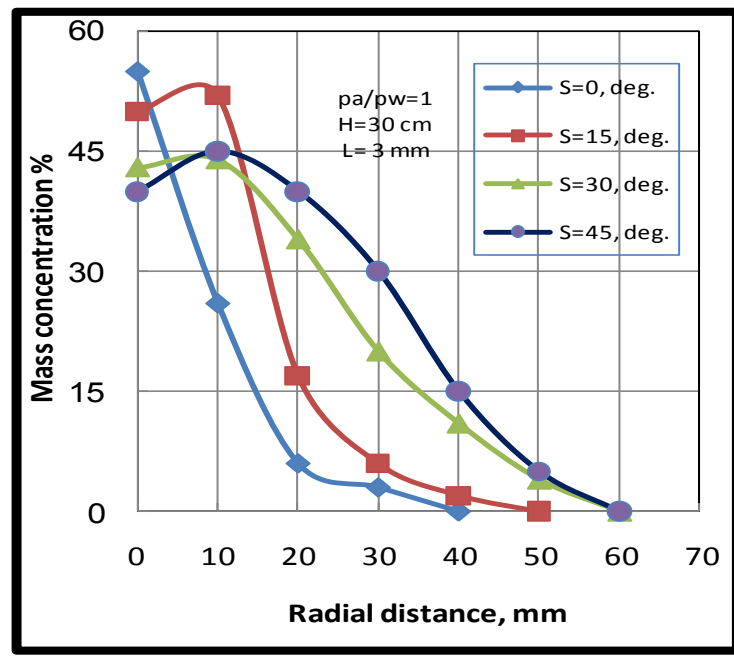

Fig. 6 Effect of swirl angle on the mass concentration

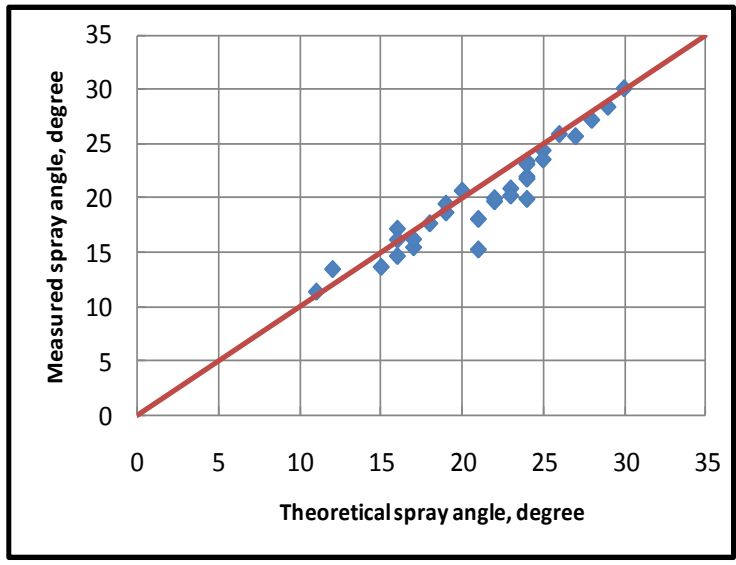

Fig. 7 Comparison of the spray angle between the experiment and the formula 